\title{
Comunicação
}

[Communication]

\section{Presença do genoma de BoHV-5 no líquido cefalorraquidiano de bovinos com meningoencefalite herpética}

\author{
[Presence of BoHV-5 genome in cerebrospinal fluid of cattle with \\ herpetic meningoencephalitis]
J.L. Massitel, J. Wesgueber, R.A.M. Oliveira, G.R. Queiroz, J.T.T. Fritzen, A.A. Alfieri, J.A.N. Lisbôa* \\ Universidade Estadual de Londrina - UEL - Londrina, PR
}

\begin{abstract}
A meningoencefalite herpética é causada pelo herpesvírus bovino 5 (BoHV-5), que acomete, principalmente, animais jovens, entre 60 dias e 18 meses de idade (Rissi et al., 2007). Essa afecção, caracterizada por baixa morbidade e alta letalidade, é considerada uma das principais causas de mortalidade por encefalite (Elias et al., 2004; Rissi et al., 2006).
\end{abstract}

Excetuando-se a raiva, a encefalite por BoHV-5 é a principal causa de encefalopatia em bovinos no Brasil, com surtos descritos nos estados de Goiás, Mato Grosso do Sul, São Paulo, Minas Gerais, Rio Grande do Sul, Mato Grosso e Pará (Rissi et al., 2007). No Paraná, alguns surtos já foram relatados, o que demonstra a importância clínica e epidemiológica da doença (Claus et al., 2007; Lisbôa et al., 2009; Lunardi et al., 2009).

Essa enfermidade causa sinais neurológicos que variam de acordo com a lesão e a área afetada do sistema nervoso central (SNC), mas geralmente caracterizam síndrome cerebral (Lunardi et al., 2009). Nistagmo, bruxismo, opistótono, amaurose, andar compulsivo, ataxia, tremores musculares e convulsões são frequentemente observados (Isernhagen et al., 2011). A evolução até a morte é variável, podendo ser de um a 15 dias (Elias et al., 2004; Isernhagen et al., 2011).

Diferentes técnicas podem ser utilizadas para a confirmação do diagnóstico post mortem, como histopatologia, imuno-histoquímica, isolamento viral e a reação em cadeia da polimerase (PCR).

Recebido em 29 de outubro de 2014

Aceito em 26 de novembro de 2015

* Autor para correspondência (corresponding author)

E-mail: janlisboa@uel.br
Para tanto, são utilizadas amostras do SNC do animal enfermo que morreu. A confirmação do diagnóstico ainda em vida tem interesse prático porque a doença nem sempre é fatal. O objetivo deste trabalho foi avaliar se a presença do genoma de BoHV-5 no líquido cefalorraquidiano (LCR), detectado por meio da PCR, pode ser admitido como método para o diagnóstico ante mortem.

Os projetos de pesquisa que originaram este trabalho foram previamente aprovados pela CEUA/UEL, sob os números de protocolo 04/09 e 32340.2012.04. Foram analisados 14 casos de bovinos naturalmente infectados com BoHV-5 e portadores de encefalite, criados em diferentes municípios do estado do Paraná. O levantamento das informações epidemiológicas, assim como os exames clínicos e neurológicos dos animais acometidos, foram realizados nas propriedades onde ocorreram os casos.

As coletas do LCR foram realizadas no espaço atlanto-occipital, utilizando-se a agulha metálica do cateter intravenoso $18 \mathrm{G}$ com $5 \mathrm{~cm}$ de comprimento (BD Angiocath) e aspiração com seringa de $1 \mathrm{~mL}$. O LCR foi mantido refrigerado até a chegada ao laboratório. A eutanásia, seguida de necropsia, foi realizada após a coleta do LCR, com a finalidade de confirmação do diagnóstico e em comum acordo com o proprietário, considerando a evolução da doença, a gravidade das manifestações clínicas e a probabilidade reduzida de resposta a tentativas de tratamentos. Fragmentos do encéfalo foram 
coletados e, posteriormente, encaminhados para os exames histopatológico e virológico (PCR). Em todos os casos, fragmentos refrigerados do encéfalo foram encaminhados para o laboratório credenciado estadual e submetidos ao método de imunofluorescência direta, descartando-se o diagnóstico de raiva.

Para o exame histopatológico, as amostras foram fixadas em formol tamponado a $10 \%$, submetidas à desidratação em soluções crescentes de alcoóis, diafanização em xilol e inclusão em parafina. Posteriormente, houve a obtenção de cortes uniformes de $5 \mu \mathrm{m}$ de espessura, com o auxílio de micrótomo, corados pelo método de hematoxilina-eosina (HE).

O LCR foi submetido à PCR, sem a etapa de extração do ácido nucleico. Nos fragmentos do encéfalo, o DNA foi extraído e submetido à PCR conforme os métodos descritos por Claus et al. (2005), com algumas modificações descritas a seguir na técnica de PCR. A reação de PCR foi realizada, utilizando-se $5 \mu \mathrm{L}$ do LCR (in natura) e $45 \mu \mathrm{L}$ de mix, constituído por $20 \mathrm{pmol}$ de cada oligonucleotídeo iniciador (primer) B5 (5'-CGG ACG AGA CGC CCT TGG- 3', nt 322-339) e Bcon (5'-AGT GCA CGT ACA GCG GCT CG3', nt 461-480); 2,0mM de dNTP (Invitrogen ${ }^{\mathrm{TM}}$ Life Technologies, EUA); cinco unidades de Taq platinum DNA polimerase (Invitrogen ${ }^{\mathrm{TM}}$ Life Technologies, EUA); 1x PCR buffer $(50 \mathrm{mM} \mathrm{KCl}$ e $20 \mathrm{mM}$ Tris- $\mathrm{HCl} \mathrm{pH} 8,4) ; 1,5 \mathrm{mM} \mathrm{MgCl} 2 ; 8 \%$ de dimetilsulfóxido (DMSO, Sigma Co., EUA) e água ultrapura estéril para completar o volume. A amplificação foi realizada em um único termociclador (PTC 200, MJ Research Co., EUA), sob as seguintes condições de tempo e temperatura: $94^{\circ} \mathrm{C}$ por $3 \mathrm{~min}$; seguido de 35 ciclos a $94^{\circ} \mathrm{C}$ por $1 \mathrm{~min} ; 58^{\circ} \mathrm{C}$ por $30 \mathrm{~s} ; 72^{\circ} \mathrm{C}$ por $1 \mathrm{~min}$ e uma extensão final de $7 \mathrm{~min}$ a $72^{\circ} \mathrm{C}$.

Foram obtidos produtos da PCR de aproximadamente $160 \mathrm{pb}$ para o gene da glicoproteína C de BoHV-5, analisados por meio de eletroforese, empregando-se gel de agarose 2\%, tampão TBE com pH 8,4 (89mM Tris; $89 \mathrm{mM}$ ácido bórico e $2 \mathrm{mM}$ EDTA) em voltagem constante $(100 \mathrm{~V})$ por aproximadamente $45 \mathrm{~min}$, corados com brometo de etídeo $(0,5 \mu \mathrm{g} / \mathrm{mL})$ e visualizados sob luz ultravioleta.

Controles positivo e negativo foram utilizados em todas as reações como indicadores da acurácia diagnóstica. Como controle positivo, empregou-se a cepa AA 01, caracterizada como BoHV-5 por imunoperoxidase com anticorpos monoclonais (Souza et al., 2002 ) e por enzimas de restrição (D’arce et al., 2002). Solução de PBS foi submetida ao processo de extração e empregada como controle negativo.

O critério de inclusão dos animais baseou-se na presença das lesões histopatológicas compatíveis com a doença, caracterizadas por meningoencefalite não supurativa com ou sem necrose, acompanhada pela presença confirmada do DNA viral em diferentes porções do encéfalo (Fig. 1).

Dos 14 casos confirmados de encefalite por BoHV-5, o genoma viral foi detectado no LCR de apenas três (Tab. 1), gerando um índice de concordância de $21,4 \%$ entre os resultados no encéfalo e no LCR. Se for considerada em termos de probabilidade, utilizando-se amostras de LCR, as chances de confirmação do diagnóstico em vida se resumiriam a, aproximadamente, dois entre 10 bovinos portadores da doença.

Estudos anteriores do mesmo grupo de pesquisa mostraram resultados divergentes, como descrito a seguir. Em um surto da doença, o DNA viral foi confirmado no LCR de dois entre cinco bezerros testados (taxa de concordância de 40\%) (Lunardi et al., 2009). Sob condições experimentais, o DNA estava presente no LCR de dois entre os quatro bezerros que desenvolveram encefalite sintomática (taxa de concordância de 50\%) (Isernhagen et al., 2011). Apesar de o número de observações ter sido baixo nos dois estudos publicados, a concordância entre as presenças do DNA viral no encéfalo e no LCR foi maior do que a comprovada no presente trabalho. 


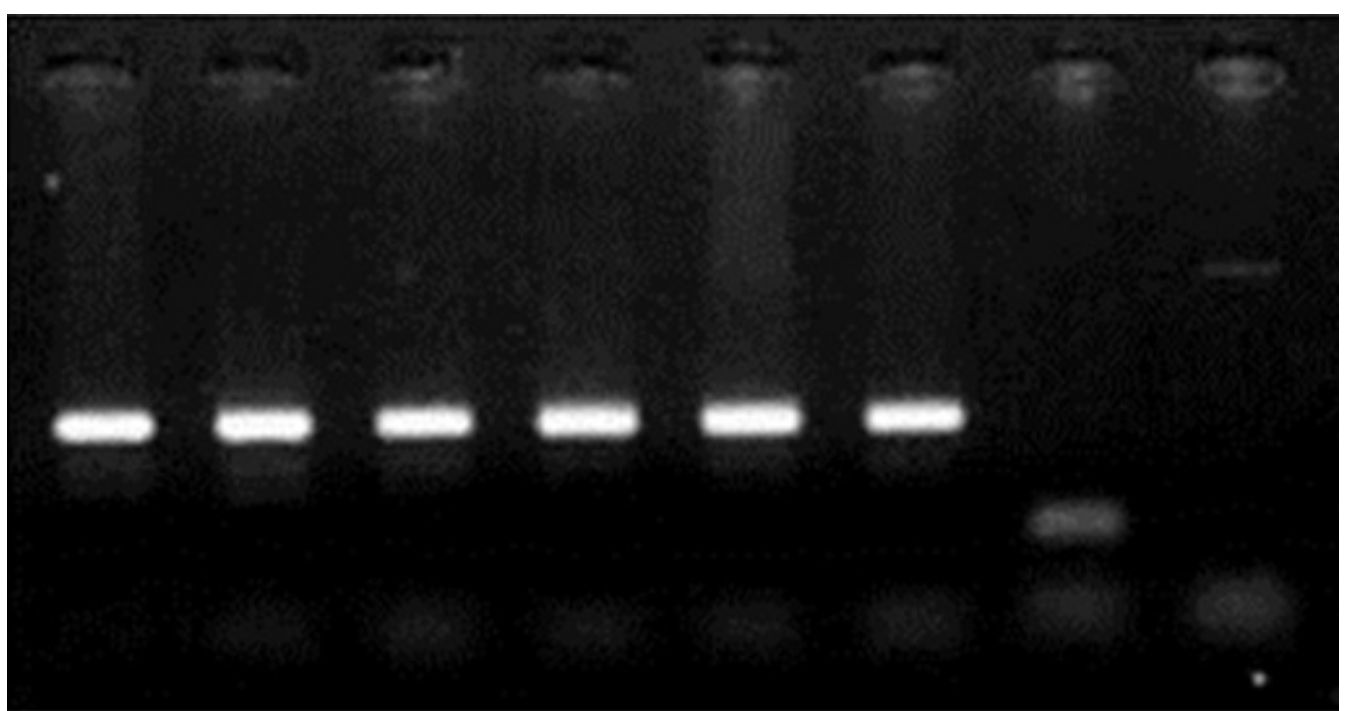

Figura 1. Eletroforese em gel de agarose a $2 \%$ com brometo de etídio dos produtos amplificados por PCR para BoHV-5 (159pb) no encéfalo e no LCR de bovinos naturalmente acometidos por meningoencefalite herpética. Linha 1: controle positivo de BoHV-5 (AA 01); linha 2: amostra de córtex positiva; linha 3: amostra de cerebelo positiva; linha 4: amostra de ponte positiva; linha 5: amostra de tálamo positiva; linha 6: amostra do gânglio do nervo trigêmeo positiva; linha 7: amostra de LCR negativa; linha 8: controle negativo (PBS).

Tabela 1. Presença do genoma de BoHV-5 no encéfalo e no LCR de bovinos naturalmente acometidos por meningoencefalite herpética

\begin{tabular}{|c|c|c|c|c|c|c|c|}
\hline RG HV & Data & Raça & $\begin{array}{c}\text { Idade } \\
\text { (meses) }\end{array}$ & Sexo & Município & Encéfalo & LCR \\
\hline $559 / 10$ & $\mathrm{Fev} / 10$ & Nelore & 24 & $\mathrm{M}$ & Ribeirão do Pinhal & + & - \\
\hline $561 / 10$ & Fev/10 & $1 / 2$ Nelore & 18 & M & Ribeirão do Pinhal & + & - \\
\hline $819 / 11$ & Mar/11 & Nelore & 16 & M & Lobato & + & + \\
\hline $918 / 11$ & Mar/11 & $1 / 2$ Nelore & 15 & M & Londrina & + & - \\
\hline $1541 / 11$ & $\mathrm{Abr} / 11$ & Nelore & 6 & $\mathrm{~F}$ & Congonhinhas & + & - \\
\hline $1840 / 11$ & Mai/11 & Nelore & 16 & $\mathrm{~F}$ & Colorado & + & - \\
\hline $2088 / 11$ & Mai/11 & Nelore & 7 & M & Sapopema & + & - \\
\hline $3725 / 11$ & Set/11 & Angus & 10 & M & Guarapuava & + & - \\
\hline $290 / 12$ & Jan/12 & Nelore & 18 & M & Bandeirantes & + & - \\
\hline $5555 / 12$ & Nov/12 & Nelore & 13 & M & Ibaiti & + & + \\
\hline $1705 / 13$ & Abr/13 & $1 / 2$ Angus & 15 & M & Jataizinho & + & - \\
\hline $4539 / 13$ & Nov/13 & Nelore & 10 & M & Bandeirantes & + & + \\
\hline $1761 / 14$ & Mai/14 & Nelore & 20 & M & Colorado & + & - \\
\hline $3405 / 14$ & Ago/14 & Nelore & 18 & M & Paranavaí & + & - \\
\hline \multicolumn{6}{|c|}{ Taxa de positividade no LCR (\%) } & & 21,42 \\
\hline
\end{tabular}

Os fatores que influenciam a presença de BoHV5 no LCR de animais com encefalite não são bem compreendidos porque não há estudos a respeito. Com base nos resultados experimentais de Isernhagen et al. (2011), a presença do DNA no LCR parece não estar relacionada com a intensidade da pleiocitose, ocorrendo em amostras que possuíam 81 e 178 leucócitos $/ \mathrm{mm}^{3}$ (dados não publicados), e é incerto que possua relação com o tempo de evolução da doença. No estudo mencionado, o DNA foi confirmado em um bezerro que morreu após quadro superagudo (12 horas de evolução) e em um bezerro que apresentou quadro prolongado, com sinais mais brandos de síndrome cerebral, e foi submetido à eutanásia com 10 dias de evolução. Nesse 
último, o DNA viral foi confirmado somente no LCR coletado ao final da evolução, tendo sido negativo nas três amostras coletadas a cada 48 horas desde o início dos sinais. Também merece destaque o fato de que, nesse mesmo estudo, a presença do DNA no LCR não foi acompanhada pelo isolamento bem-sucedido do agente, distintamente do que se observou nas amostras coletadas de diferentes locais do encéfalo. Sob condições de infecção experimental, Spilki et al. (2006) também não obtiveram sucesso no isolamento viral em amostras de LCR.

Nos bovinos incluídos no presente estudo, o tempo de evolução até a morte foi variável (entre 24 horas e oito dias) e o número de células nucleadas presentes no LCR variou, consideravelmente, de 16 a 463 leucócitos $/ \mathrm{mm}^{3}$. O DNA foi confirmado no LCR de animais que tinham doença há 24 horas, quatro dias e cinco dias, e intensidade de pleiocitose distinta: 16, 93 e 463 leucócitos $/ \mathrm{mm}^{3}$; curiosamente, os extremos da variação.

Segundo estudo realizado com 15 cães naturalmente infectados pelo vírus da cinomose canina (CDV) e portadores de encefalite, a fase da doença (aguda ou crônica) e a gravidade e extensão das lesões presentes podem influenciar o número de células infectadas no LCR (Amude, 2008). O genoma do vírus foi identificado no LCR de 53,3\% dos cães (8/15), e os resultados positivos foram mais prováveis na fase aguda da encefalite do que na crônica. Assim como já discutido para os bovinos, a presença do genoma do CDV no LCR também não se correlacionou com a intensidade da pleiocitose presente. Ainda que a comparação entre vírus distintos infectando hospedeiros diferentes não seja a mais adequada, fica patente que a presença do agente viral no LCR de animais com encefalite é, provavelmente, influenciada por diferentes fatores, que ainda não estão suficientemente esclarecidos.

A meningoencefalite herpética é uma doença que apresenta índice de letalidade elevado, mas nem sempre ocasiona a morte, tanto em surtos naturais (Lisbôa et al., 2009; Lunardi et al., 2009) quanto em infecções experimentais (Isernhagen et al., 2011). A confirmação do diagnóstico em vida tem importância nos casos não fatais da enfermidade, mas, mesmo nos casos que resultarão em morte, pode permitir o estabelecimento precoce do diagnóstico diferencial com outras doenças nervosas. Com base nos resultados obtidos, pode-se concluir que a pesquisa da presença do genoma de BoHV-5 no LCR é um método de diagnóstico limitado. O resultado positivo no LCR confirma o diagnóstico, mas o resultado negativo não descarta a possibilidade de ser a enfermidade.

Palavras-chave: herpesvírus, diagnóstico, PCR, líquor

\begin{abstract}
The diagnosis of bovine herpesvirus 5 (BoHV-5) encephalitis is confirmed after death by laboratory methods applied to brain fragments. Alternative methods to confirm ante-mortem diagnosis are important because the disease is not always lethal. The aim of this study was to investigate whether the presence of the virus genome in the cerebrospinal fluid (CSF) detected by polymerase chain reaction (PCR) might be admitted as a method for ante-mortem diagnosis. CSF samples were taken from 14 animals suffering from BoHV-5 encephalitis, diagnosed by characteristic histopathological lesions in the brain and by identification of the virus genome by PCR in different portions of the brain. Virus DNA was detected in the CSF of $21.42 \%$ (3/14) of the evaluated animals. Ante-mortem detection of the virus genome in the CSF showed low sensitivity to confirm the diagnosis. The diagnosis is confirmed by a positive result but a negative one does not discard the disease.
\end{abstract}

Keywords: herpesvirus, diagnosis, PCR, liquor

\section{AGRADECIMENTOS}

Ao Mapa e ao $\mathrm{CNPq}$, pelo apoio financeiro (Mapa/CNPq, processo $\mathrm{n}^{\mathrm{o}} 9578645 / 2008-4$ e CNPq processo $\left.\mathrm{n}^{\mathrm{o}} 478254 / 2012-1\right) ;$ aos professores Ana Paula F.R.L. Bracarense,
Antônio Carlos F. dos Reis, Giovana W. di Santis e Selwin A. Headley, pela realização dos exames histopatológicos na rotina de diagnóstico. A.A. Alfieri e J.A.N. Lisbôa são bolsistas de produtividade em pesquisa do CNPq. 


\section{REFERÊNCIAS}

AMUDE, A.M. Encefalomielite pelo virus da cinomose canina: aspectos neuroclinicos $e$ neuropatológicos e uso das técnicas de RT-PCR e imunohistoquímica no auxilio do diagnóstico Post mortem. 2008. 216f. Tese (Programa de Pós-Graduação em Ciência Animal) Universidade Estadual de Londrina, Londrina, PR.

CLAUS, M.P.; ALFIERI, A.F.; FOLGUERASFLATSCHART, A.V. et al. Rapid detection and differentiation of bovine herpesvirus 1 and 5 glycoprotein $\mathrm{C}$ gene in clinical specimens by multiplex-PCR. J. Virol. Methods, v.128, p.183$188,2005$.

CLAUS, M.P.; ALFIERI, A.F.; MÉDICI, K.C. et al. Bovine herpesvirus 5 detection by virus isolation in cell culture and multiplex-PCR in central nervous system from cattle with neurological disease in brazilian herds. Braz. J. Microbiol., v.38, p.485-490, 2007.

D'ARCE，R.C.F.; ALMEIDA, R.S.; SILVA, T.C. et al. Restriction endonuclease and monoclonal antibody analysis of Brazilian isolates of bovine herpesviruses types 1 and 5 . Vet. Microbiol., v.18, p.315-324, 2002.

ELIAS, F.; SCHILD, A.L.; RIET-CORREA, F. Meningoencefalite e encefalomalácia por herpesvirus bovino-5: distribuição das lesões no sistema nervoso central de bovinos naturalmente infectados. Pesqui. Vet. Bras., v.24, p.123-131, 2004.
ISERNHAGEN, A.J; COSENZA, M.; COSTA, M.C.C. et al. Asymtomatic encephalitis in calves experimentally infected with bovine herpesvirus5. Can. Vet. J., v.52, p.1312-1318, 2011.

LISBÔA， J.A.N.; ISERNHAGEN, A.J.; BORGES, A.S. et al. Hematological and cerebrospinal fluid changes in cattle naturally and experimentally infected with the bovine herpesvirus 5. Braz. Arch. Biol. Technol., v.52, p.69-76, 2009.

LUNARDI, M.; CLAUS, M.P.; LISBÔA, J.A.N. et al. Neurological and epidemiological aspects of BoHV-5 meningoencephalitis outbreak. Braz. Arch. Biol. Technol., v.52, p.77-85, 2009.

RISSI, D.R.; OLIVEIRA, F.N.; RECH, R.R. et al. Epidemiologia, sinais clínicos e distribuição das lesões encefálicas em bovinos afetados por meningoencefalite por herpesvirus bovino-5. Pesqui. Vet. Bras., v.26, p.123-132, 2006.

RISSI, D.R; RECH, R.R; FLORES, E.F.et al. Meningoencefalite por herpesvírus bovino-5. Pesqui. Vet. Bras., v.27, p.251-260, 2007.

SPILKI, F.R.; SILVA, T.C.; ESTEVES, P.A. et al. Co-infections with bovine herpesvírus type 5 and bovine viral diarrhoea virus. Arq. Bras. Med. Vet. Zootec., v.58, p.699-707, 2006.

SOUZA, V.F.; MELO, S.V.; ESTEVES, P.A. et al. Caracterização de herpesvírus bovinos tipos 1(BHV-1) e 5 (BHV-5) com anticorpos monoclonais. Pesqui. Vet. Bras., v.22, p.13-18, 2002. 